\title{
Evaluating Model and BeiDou Based Management System for Scale Operation of Cotton-Pickers
}

\author{
Caicong $\mathrm{Wu}^{1,2}$, Peng Qiao' ${ }^{1}$, Jing Zhao ${ }^{1}$, Jie Wang1, Yaping Cai ${ }^{3}$ \\ ${ }^{1}$ College of Information and Electrical Engineering, China Agricultural University, Beijing, China \\ ${ }^{2}$ Department of Soil \& Crop Sciences, Texas A\&M University, College Station, USA \\ ${ }^{3}$ Department of Geography and Geographic Information Science, UIUC, Champaign, USA \\ Email:wucc@cau.edu.cn, caicai_pku@163.com
}

Received 7 December 2015; accepted 18 January 2016; published 21 January 2016

Copyright (C) 2016 by authors and Scientific Research Publishing Inc.

This work is licensed under the Creative Commons Attribution International License (CC BY).

http://creativecommons.org/licenses/by/4.0/

(c) ()) Open Access

\section{Abstract}

For scale cotton-picker operation, combination of production resources including field, machine, and drivers, should be organized reasonably both in temporal and spatial dimensions. Xinjian Agri. is such a scale cotton picking service company, which owns more than 400 cotton-pickers, hires nearly 1000 personnel, and works for more than ten big farms each season. The total operation area is about 90,000 ha. In this paper, a Cotton-picker Operation Scheduling \& Monitoring System (CPOSMS) was developed for Xinjian Agri. CPOSMS is a WebGIS and BeiDou based management software, which includes four main function modules. Overall scheduling module aims to help the company to create machine fleets for the farms based on operation demands and operation capacity. A real-time evaluation model was studied to adjust the rationality. Local scheduling module is to dispatch machines and personnel to form machine unit. Central navigating module is to guide staff to specific field. Operation monitoring module is to monitor and analyze operation process. Experiments in 2015 showed that the CPOSMS is the necessary tool for the company, and the evaluation model and BeiDou based system can improve management efficiency.

\section{Keywords}

Cotton-Picker, Operation Scheduling, Model, System, BeiDou

\section{Introduction}

Overall scheduling, dispatching, navigating, and monitoring are quite important for bigsocial service companies 
and cooperatives of farm machinery. These kinds of organization are being encouraged and supported by Chinese government, which provides mechanical, professional, and commercial service for small farmers or plantation farms. The separation of property rights is the obvious characteristic of this kind of organization. Field, crop, and machine do not belong to drivers, who are hired by the organization usually. Xinjiang Xinjian Modern Agricultural Engineering Development Co., Ltd. (Xinjian Agri.) is such a company which owns more than 400 cotton-pickers of CASE IH and John Deere, and nearly half of cotton area of Shihezi, Xinjiang, is harvested by the company. It is a classical B2B (Business to Business) commercial mode to provide social service for some large county farms with about 9000 ha cotton field. Small farmers were organized by the local government and the latter would sign contract with Xinjian Agri. Xinjiang is a province with wide area and complicated road, fleet management and guidance is quite important for Xinjian Agri. Production resources including field, machine, and personnel, should be managed, allocated, and scheduled scientifically both intemporal and spatial dimensions, to ensure harvesting task can be completed orderly.

Scheduling is the decision-making process that deals with the allocation of resources to tasks over given time periods and its goal is to optimize one or more specific objectives [1]. Some research concluded that the execution of an optimal schedule was found to give a reduction of $9.8 \%$ in the total time as compared to a schedule based on the tacit knowledge of the operations manager [2]. Several approaches for scheduling in field operations have been proposed including stochastic programming [3], hybrid petri nets [4], and metaheuristics [5]. The approaches for multiple-machinery systems also have been proposed for biomass harvesting [6]. However, there are some differences between the above research and action of Xinjian Agri. The obvious difference is that the cotton-picker will stay in specific farm for whole season. The company needs evaluation model to help them to allocate machines more effectively and fairly.

Global Navigation Satellite System (GNSS) is widely used for fleet management nowadays [7] [8]. GNSS terminal [9] [10] is usually equipped on the farm machine to capture real-time fleet positions, public CAN messages, and fleet productivity information [11]. These data would be transferred to server through cellular network for production management and remote diagnosis [12]. GNSS was also used to calculate operation area [13] [14]. By using RTK or DGPS [15], we can survey field boundary to get accurate digital map and geometric area. It is a precise method but the outwork is quite large. For tractor with dual-frequency RTK receiver, they can easily get operation area. But high accuracy RTK system is not affordable for many social service organizations, and it is nearly impossible to receive dual-frequency correction signal. For some advance machines [16], they can measure operation area by using odometer and CAN messages, such as status of header, fan, and ground speed. Therefore, it is a good choice to use GNSS terminal with CAN interface to realize remote monitoring and operation economically [17]. Cotton-picker is a kind of professional machine; different brands have different CAN protocols. So GNSS terminal for cotton-picker should be developed.

In fact, GNSS based fleet management and farm management software, such as Connected Farm of Trimble, Telematics of CLAAS, AFS Connect of CASE IH, SMS of AgLeader, Farm Sight of John Deere, is gradually used by farmers in developed countries [18]. This kind of WebGIS based software can manage field, crop, and machines, and help farmers to improve their productivities. Besides management requirement, for social service company, it is important to accurately guide machine unit to specific field every day and to support project manager to monitor and provide emergency service for scattered machine unit. As a stranger in the farm, drivers usually feel difficult to find the exact field. So the authors proposed central navigating technology for guiding the driver to destination field [19]. And smartphone based APP is developed for mobile monitoring and mobile commanding [20].

In face of the management and schedule requirements of Xinjian Agri., the authors designed and developed a Cotton-Picker Operation Scheduling \& Monitoring System (CPOSMS), in order to help the company to schedule combination of production factors effectively and fairly, and support mobile management in the farm. We did not try to build a system to replace of the brain of human beings. On the contrary, the CPOSMS just encourages managers to schedule machines and personnel, and evaluates the decisions in real-time, in order to improve scheduling efficiency and accuracy.

\section{Materials and Methods}

\subsection{Workflow and System Structure}

As Figure 1, there are mainly six steps to finish cotton harvesting operation. The first step is to sign harvesting 


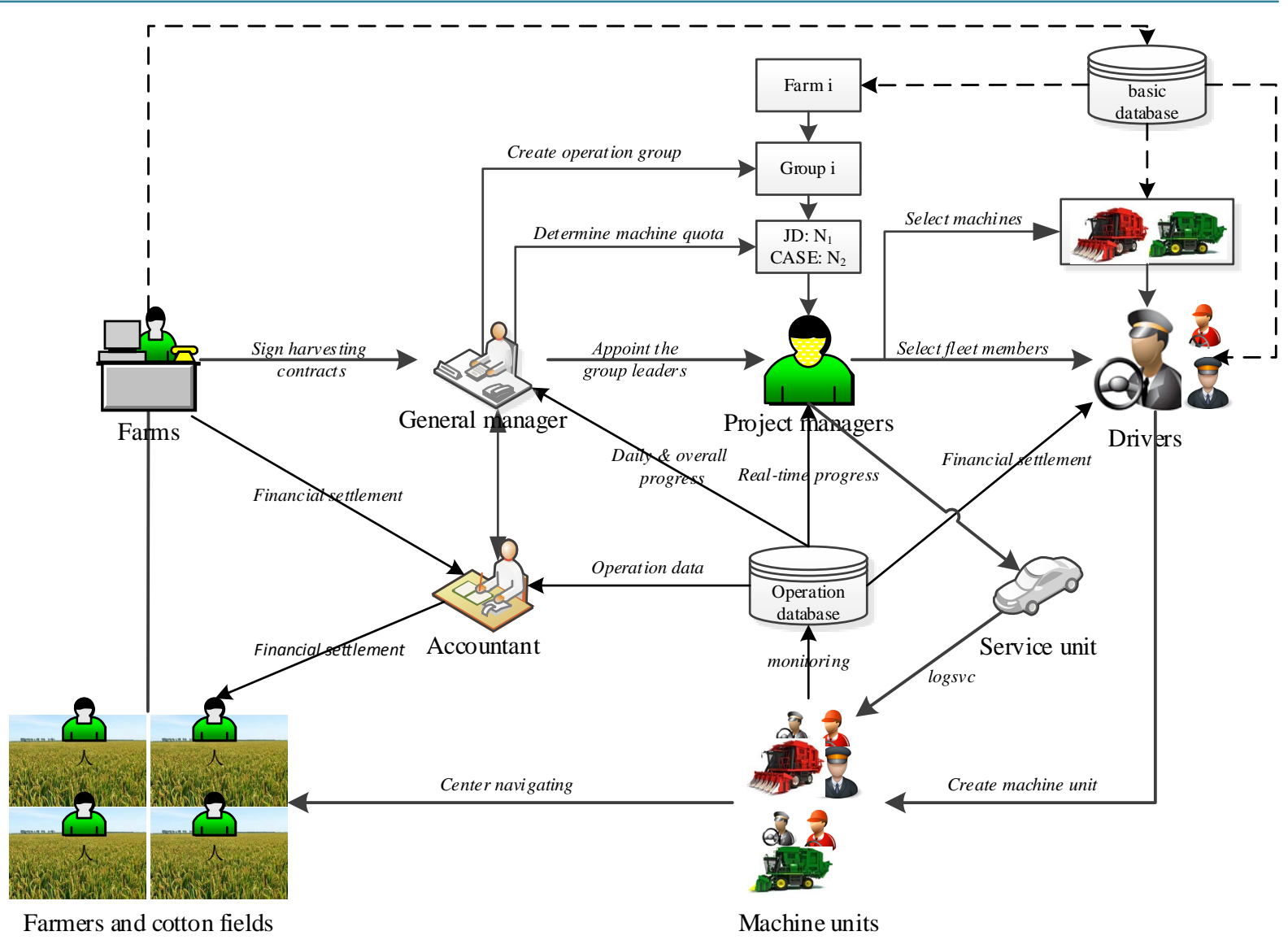

Figure 1. Workflow of cotton-picker operation scheduling and management of Xinjian Agri.

contracts with local farms, which would organize small farmers together. The second step is to create machine fleet for the farms, to determine machine quota (machine type and amount) according to operation area of the farms, and to appoint project managers (fleet captain) by general manager. He should allocate machines fairly and ensure all the orders can be finished in time. The third step is to select specific machines and personnel to establish machine unit (MU). Drivers will work with the machine during harvesting season. Other people will help them to ensure logistic service, such as fuel and parts supplying, and emergency repairing. The fourth step is to guide machine unit to fields by project manager. The fifth step is to monitor and statistic operation progress by project managers and general manager. The last step is to make financial settlement with farms and drivers.

According to the workflow of cotton-picker operation scheduling and management, a Cotton-picker Operation Scheduling \&Monitoring System (CPOSMS) was designed and developed. System structure of CPOSMS is as Figure 2. The components, users, and functions were shown in Table 1.

\subsection{Overall Operation Scheduling}

The cotton harvesting operation would be organized by local farms each year. The farms, like the counties in other provinces of China, have about 9000 ha farmland. The farmlands belong to the state but are rented by farmers. They should plant prescribed crop according to plantation plan of local government. Before cotton picking, the farms would sign contracts with social service companies to ensure total completion of harvest tasks of all farmlands, as well as to improve picking quality and reduce picking cost. In fact, in Shihezi, half of picking market was occupied by Xinjian Agri., and others would be shared by some individuals or small cooperatives.

Xinjian Agri. would establish one or more machine fleets for each farm. Usually, the amount of cotton-picker will not more than 25 for a single machine fleet. Since different cotton-picker has different picking capacity and need different personnel, the general manager will just determine machine quota. For example, 5-row cottonpicker can harvest about 220 ha per season, while 6-row cotton-picker can harvest some 267 ha per season. 


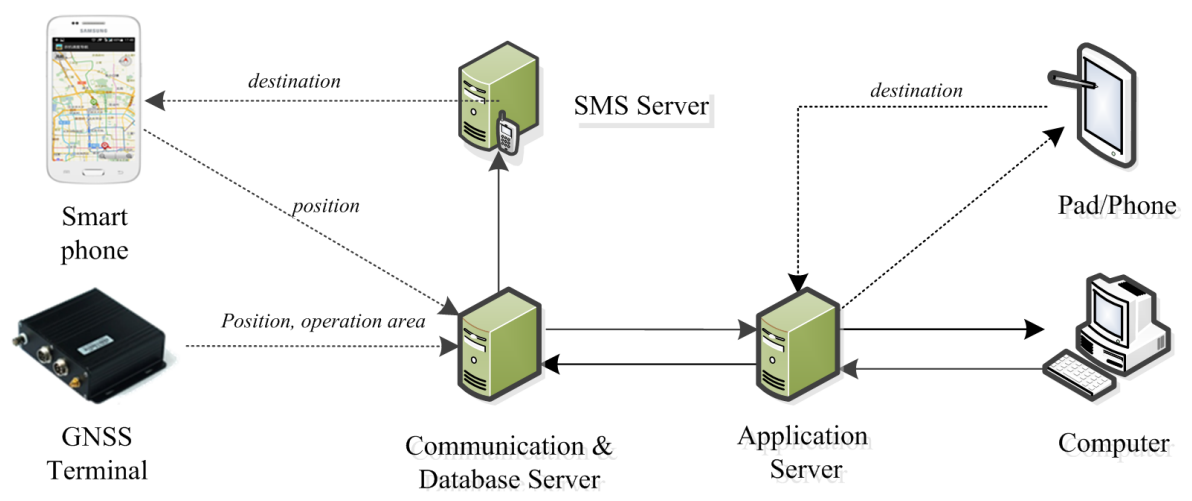

Figure 2. Structure of cotton-picker operation scheduling \& monitoring system.

Table 1. Components and functions of the cotton-picker operation scheduling \& monitoring system.

\begin{tabular}{|c|c|c|}
\hline Component & User & Function \\
\hline GNSS terminal & Cotton-picker & Positioning and reporting operation area \\
\hline Smart phone & $\begin{array}{l}\text { Captain of machine unit, } \\
\text { driver of service unit }\end{array}$ & $\begin{array}{l}\text { Positioning and receiving } \\
\text { central navigating message }\end{array}$ \\
\hline SMS server & & Repeating central navigating message \\
\hline Communication \& database server & & Receiving, managing, and repeating message \\
\hline Application server & & Supporting client visiting \\
\hline Computer & General manager and accountant & Monitoring, analyzing, and management \\
\hline Pad/Phone & Fleetmanagers & Mobile monitoring and commanding \\
\hline
\end{tabular}

The 6-row cotton-picker is much more welcomed than 5-row cotton-picker by farmers. Another notification should be mentioned is that each John Deere (JD) cotton-picker need two drivers, while CASE cotton-picker need an additional security person to monitor potential fire in cotton box.

As a result, the overall scheduling module is to help the general manager to create machine fleet and determine the amount of different types of cotton-pickers. Evaluation model for overall scheduling would evaluate overall demands of cotton-picker from farms and overall supply capacity of cotton-picker of the service company. The CPOSMS use graphical interface to help the managers to evaluate their appointments. And the formula of evaluation model as Equation (1):

$$
P_{i}=\frac{\sum_{j=1}^{n} B_{j} N_{i j}}{A_{i}} \times 100 \%
$$

where $P_{i}(\%)$ is the estimated completion rate of order $i(i=1,2, \cdots, m), A_{i}($ ha) is cotton plantation area of oder $i$, $B_{j}$ (ha per season)is estimated operation capacity of cotton-picker $j(j=1,2, \cdots, n), n$ is the amount of cottonpicker type (usually $n=2$ ), and $N_{i j}$ is the machine amount of type $j$ for order $i$.

It is reasonably that $P_{i}$ would be equal to or higher than $100 \%$, which means that machine fleet can finish operation order independently and is competent for its task. But usually the value is somewhat lower than $100 \%$, which may keep some pressure to drivers and encourage them to work harder. But when $P_{i}$ is lower than $90 \%$, it is difficult for machine fleet to finish its task. So during overall operation scheduling, evaluation model will give value of $P_{i}$ for the general manager to notify him to determine the quota of machine fleet reasonably.

The objective functions of the evaluation model as Equation (2) and Equation (3):

$$
\begin{aligned}
& \max \{\bar{P}\} \\
& \min \{\delta\}
\end{aligned}
$$




$$
\begin{gathered}
\bar{P}=\frac{\sum_{i=1}^{m} P_{i}}{m} \times 100 \% \\
\delta=\frac{\sum_{i=1}^{m}\left|P_{i}-\bar{P}\right|}{m}
\end{gathered}
$$

The whole target we pursue is to maximize the average operation completion rate, as Equation (2), and to minimize the difference of the completion rate, as Equation (3). Since the amount of cotton-picker is numerous, the real time evaluation model is useful for the overall operation scheduling.

\subsection{Local Operation Scheduling}

Local operation scheduling module is to help manager of machine fleet to choose appropriate cotton-pickers and personnel to fill in his machine units. One captain and one assistant driver are necessary for both of JD cotton-picker and CASE cotton-picker, but an additional security person is also needed for CASE cotton-picker. Each machine unit would be appointed to a specific farm.

\subsection{Central Dispatching and Navigating}

Central navigating module will help the manager of machine fleet to send operation task description and the destination of the farmland to the captain. A smart phone based APP was developed to receive short message and to guide machine units to specific farms and farmlands. The APP will identify the text format automatically, generate the optimum path by Baidu map, and guide the machine unit to the destination.

The short message format is as following:

\section{header:time:longitude:latitude:destination:end.}

where, header is the start identification of central navigating message, time is the date and time when message sent, longitude is the longitude of destination, latitude is the latitude of destination, destination is the destination name and task description, end is the end identification of central navigating message. The fields are separated by colon (:).

Three kinds of central navigating mode for mobile location-based services including V2F, V2V, and V2A, are defined as Figure 3 and Table 2.

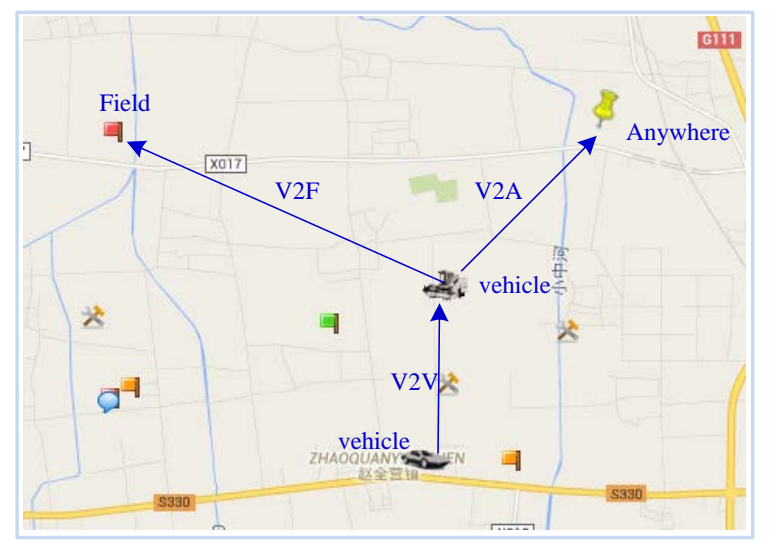

Figure 3. Central navigating mode for mobile location-based services of farm machinery.

Table 2. Central navigating mode and illustration for mobile location-based services.

\begin{tabular}{ccc}
\hline Mode & Illustration & \multicolumn{1}{c}{ Usage } \\
\hline V2F & Vehicle to field & To guide the machine unit to specific farm or field \\
V2V & Vehicle to vehicle & To guide the service unit to machine unit in the field \\
V2A & Vehicle to anywhere & To guide the machine unit to anywhere when needed \\
\hline
\end{tabular}




\subsection{Operation Monitoring and Statistic}

As Figure 4, each cotton-picker was equipped with GNSS terminal, dot matrix display, TTS voice broadcast terminal, and infrared night vision camera. The GNSS terminal uses Unicore UM220 BeiDou/GPS chip. The terminal is connected to CAN bus of cotton-picker, so it can receive the information including header status, rotate velocity of fan, and ground speed of GNSS, as shown in Figure 5.

With the working status parameters, both of operation distance of each row and harvesting area can be calculated in real time. Position of cotton-picker and operation area of independent field can be transmitted to servers and operation database by GPRS. The above information is reference for financial settlement.

\section{Model and System Test}

During cotton picking season of 2014, the authors worked with Xinjiang Xibuyinli Mechanical Cotton Picking Co., Ltd. (Xibuyinli) to schedule its cotton-pickers. Xibuyinli had 99 cotton-pickers. In 2015, Xibuyinli merged with Xinjian Agri. to form the New Xinjian Agri. The new company totally has more 400 cotton-pickers and about 357 of them were used for cotton picking in 2015. In September, 2015, 431 farm machinery including all cotton-pickers were equipped with GNSS terminal. The authors help the manager to use the CPOSMS, and tracked whole picking process.

\section{Results}

\subsection{Overall Operation Scheduling}

As Figure 6, the general manager not only can judge completion rate of current machine fleet, but also can compare completion rate of entire machine fleets. With histogram, his scheduling work became easier than before. For big farm, such as Farm 121, Farm 133, Farm 134, Farm 148, and Farm 149, they were allocated two or three machine fleets. According to operation order and operation capacity, the average completion rate $\bar{p}=$ $101.9 \%, \sigma=6.3 \%$. These parameters showed that all the orders can be finished, and the deviation is acceptable. The company can adjust machine units among farms or finish the order by extend operation duration. Practice showed that the operation scheduling accorded with the reality. All the machine fleets finished they task in 2015 in time.

\subsection{Local Operation Scheduling}

As Figure 7, local operation scheduling module can assist the manager of machine fleet to select cotton-pickers and personnel, to fill in his machine units. He will accompany his machine units for the whole picking season.

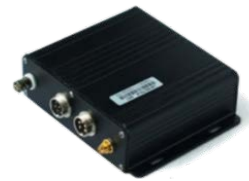

(a)

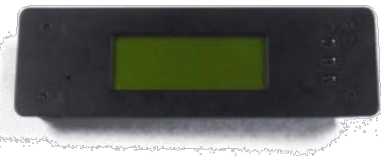

(b)

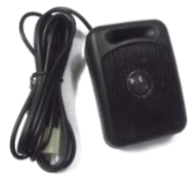

(c)

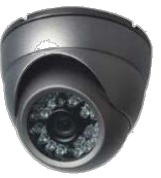

(d)

Figure 4. (a) GNSS (BeiDou/GPS) terminal; (b) Dot matrix display connected to the GNSS terminal; (c) TTS voice broadcast terminal; (d) Infrared night vision camera connected to the GNSS terminal.

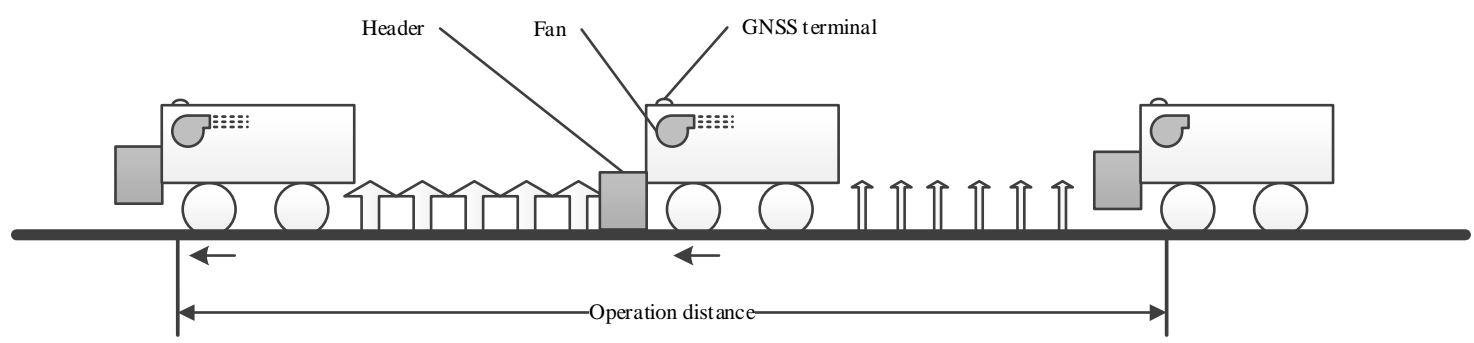

Figure 5. Operation distance calculated by GNSS terminal with header status, rotate velocity offan, and ground speed of GNSS. 


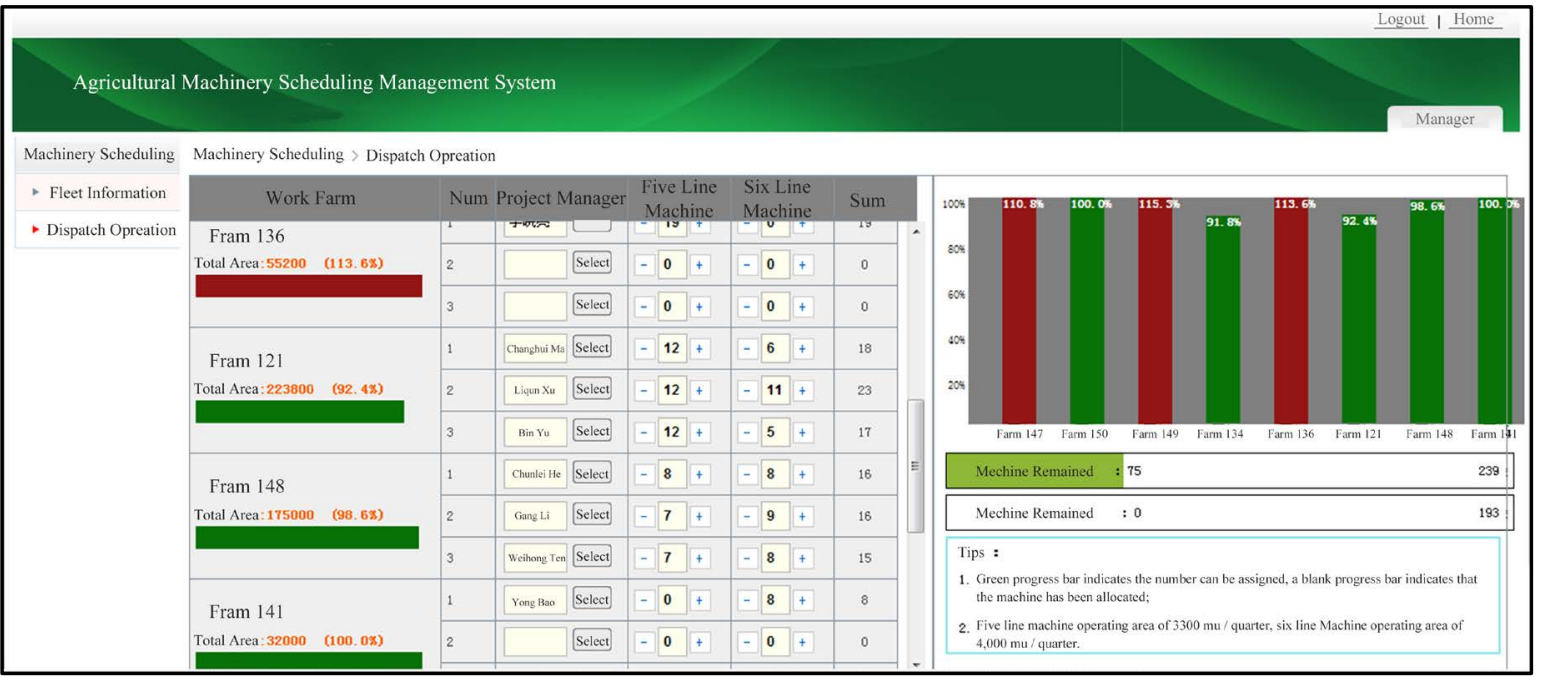

Figure 6. The interface of overall operation scheduling to allocate cotton-picker quota and to create machine fleet.

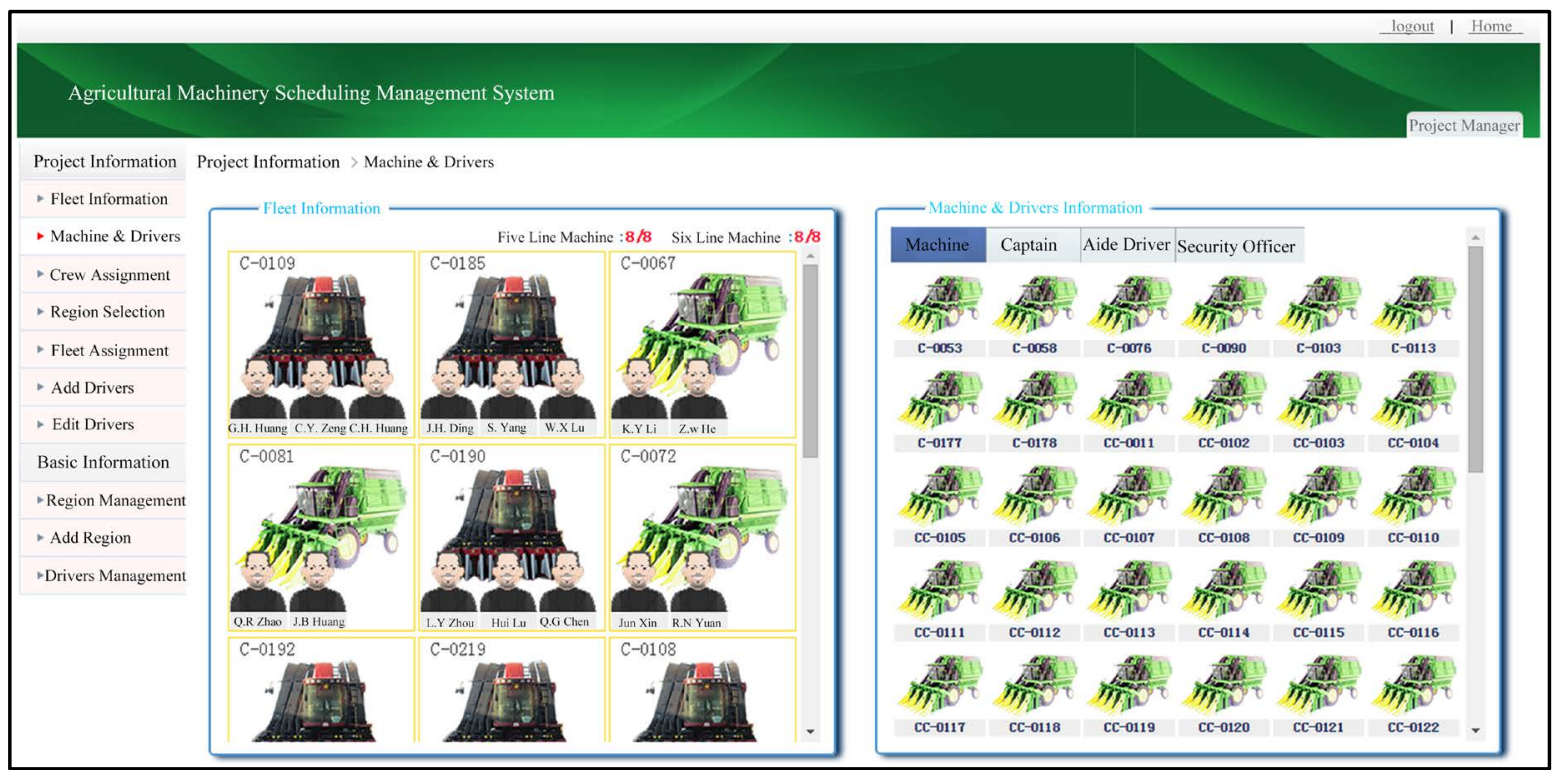

Figure 7. Interface of local operation scheduling to create machine unit by dragging icon of cotton-picker and personnel including captain, assistant driver, and (or) security person from database. The center interface shows machine units, the right interface shows alternative machines and personnel.

\subsection{Central Dispatching \& Navigating}

By using smartphones, fleet manager can establish wireless communication and navigation network with his machine units. As Figure 8 shows, he could guide them to specific field everyday by using the central navigating method. Of course, he can also guide service unit to specific machine unit when they suffered with breakdown.

\subsection{Operation Monitoring}

As Figure 9 and Figure 10, Baidu and Google map were used for cotton-picker monitoring. From the interface, the manager can capture most of the information about the cotton picking operation.

As Figure 11, the manager can replay cotton-picker's historical operation tracks to enquire ground speed, rotate velocity of fan, status of header, current operation area, and total operation area of cotton-picker. 
C. C. Wu et al.

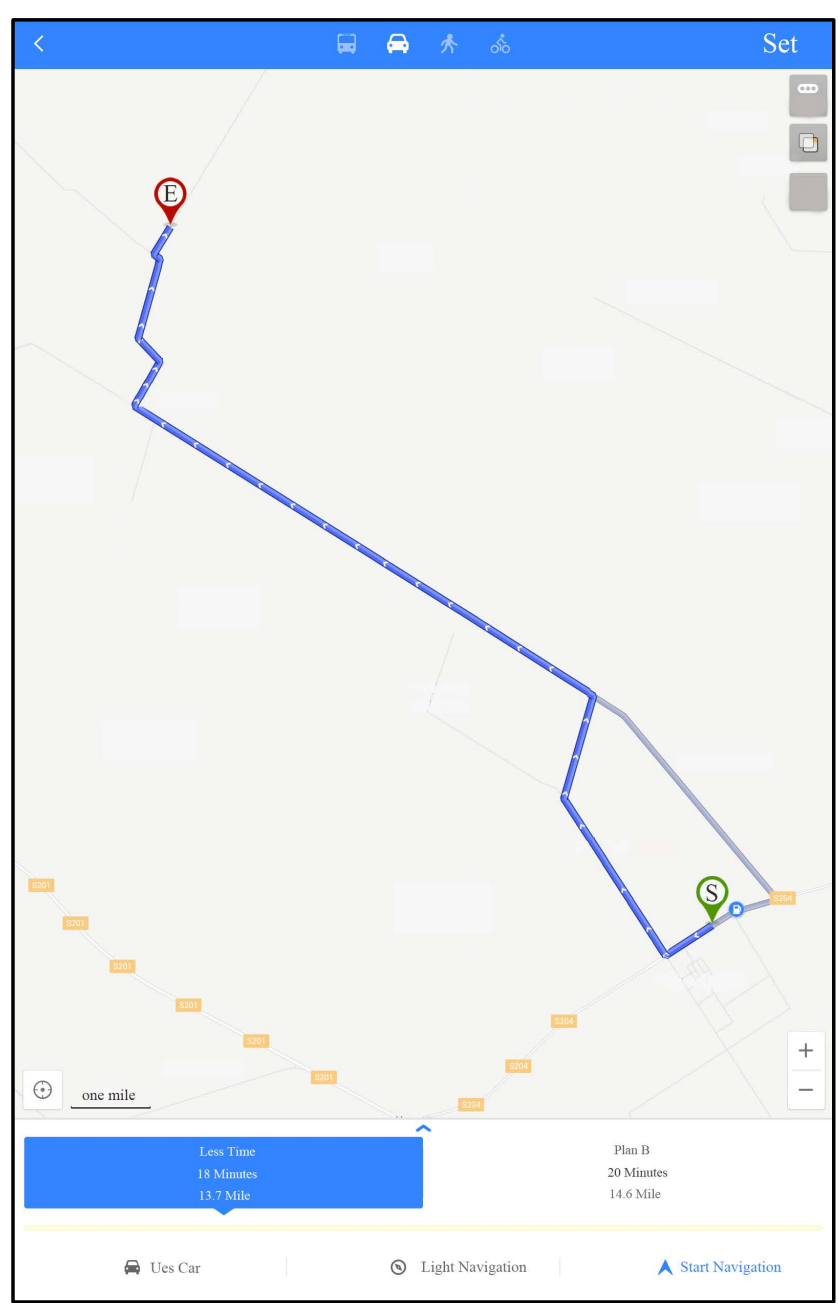

Figure 8. Interface of central navigating from vehicle to field.

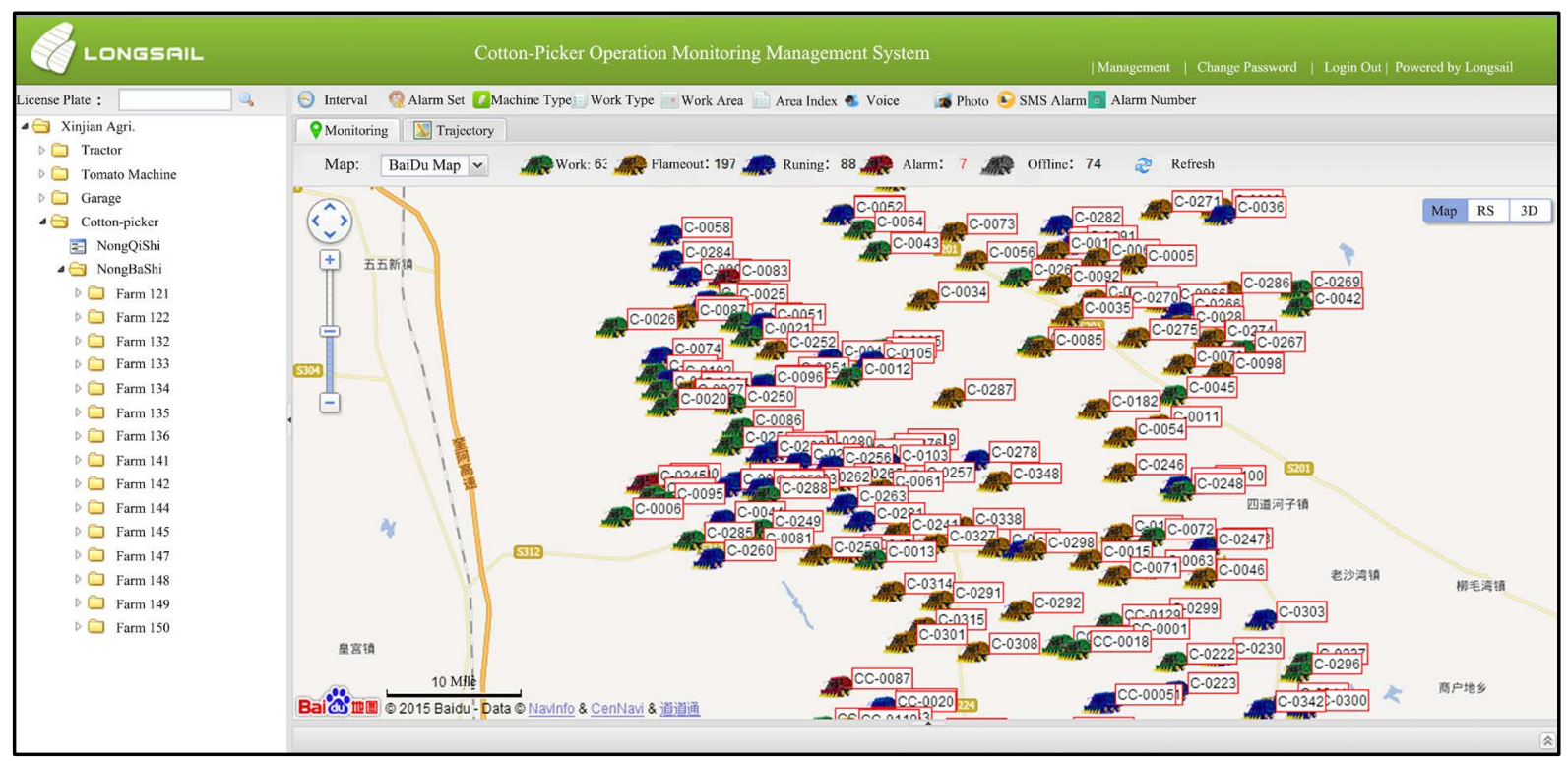

Figure 9. Interface of operation monitoring of CPOSMS.

28 


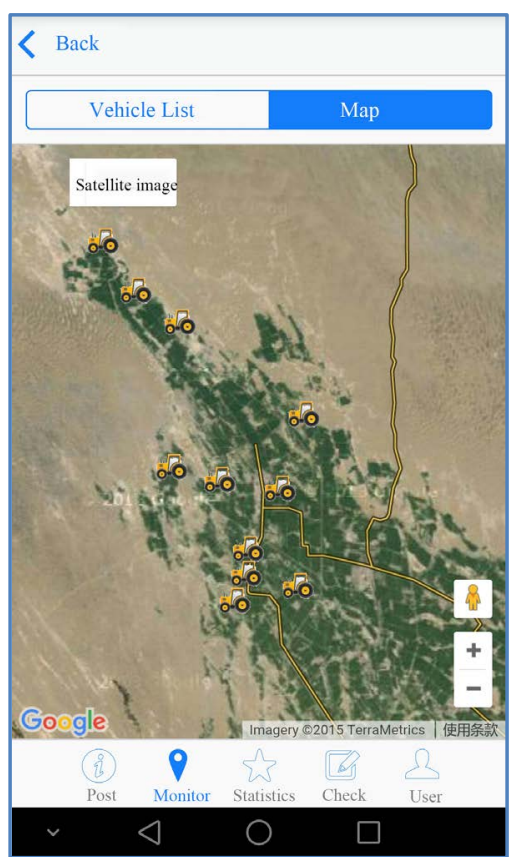

(a)

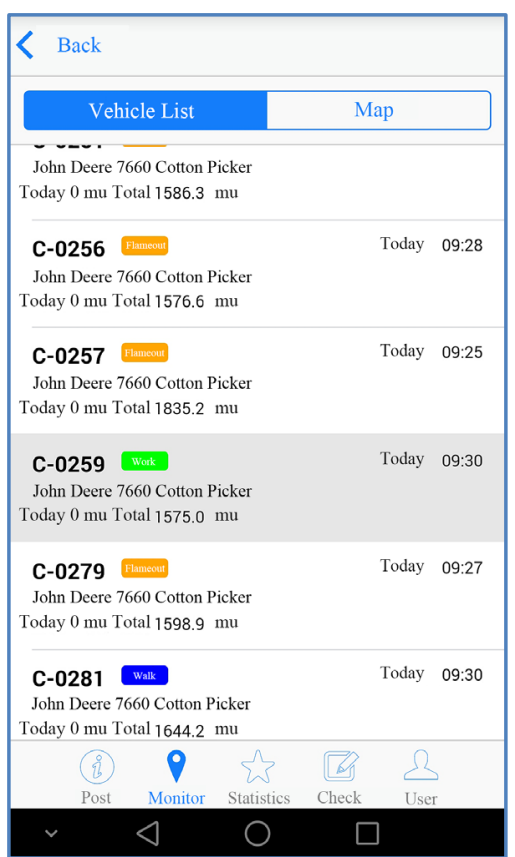

(b)

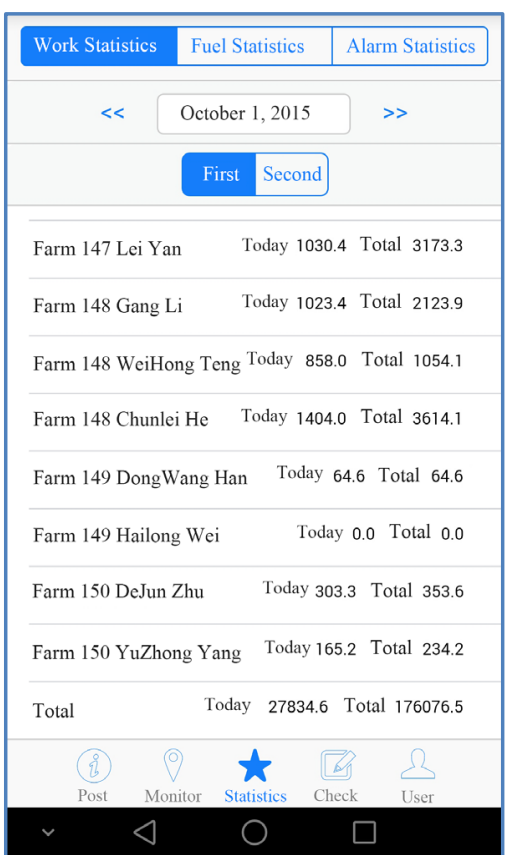

(c)

Figure 10. APP for smartphone. (a) Shows monitoring interface; (b) Shows progress of machine unit; (c) Shows progress of machine fleet.

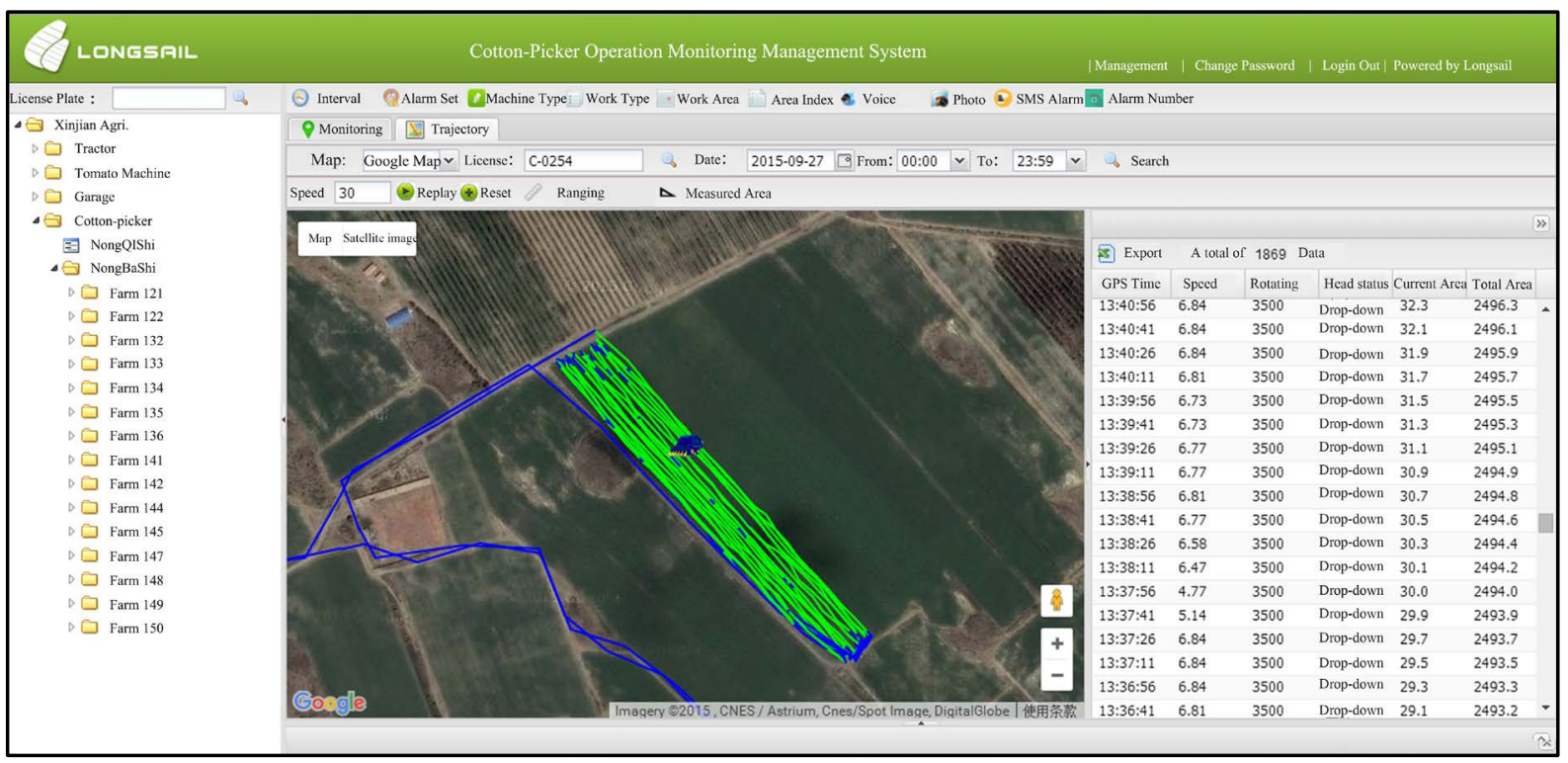

Figure 11. Operation tracks replaying of CPOSMS.

\section{Conclusions and Discussions}

Cotton-Picker Operation Scheduling \& Management System (CPOSMS) was developed for the scale company providing social cotton picking service. It is a classical B2B commercial business mode. In general, the CPOSMS concludes four main functions: overall operation scheduling, local operation scheduling, central dispatching and navigating, and operation monitoring. The system covers the whole action of the cotton-picker company. Experiments of two years showed that the system has been the essential tool for Xinjiang Xinjian Modern Agricultural Engineering Development Co., Ltd. (Xinjian Agri.). 
Due to the objective existence of uncertainty influence factors, the CPOSMS cannot produce invariable scheme to guide the whole operation. That is the reason why we proposed to develop the assistant method and software. And we do not try to replace the brain of human beings by using the software. It is still a hard challenge to improve the usage of artificial intelligence in agricultural production which has various uncertainties.

\section{Acknowledgements}

This work is in part supported by National High Technology Research and Development Program of China (2012AA101902), Science \& Technology Pillar Program of Tianjin (14ZCZDNC00004), and part supported by Chinese Universities Scientific Fund (2014RC015). Thanks for the support from Xinjiang Xinlangdi Technology Development Co., Ltd.

\section{References}

[1] Pinedo, M.L. (2012) Scheduling: Theory, Algorithms, and Systems. Springer, NY, USA. http://dx.doi.org/10.1007/978-1-4614-2361-4

[2] Bochtis, D.D., Dogoulis, P., Busato, P., Sørensen, C.G., Berruto, R. and Gemtos, T. (2013) A Flow-Shop Problem Formulation of Biomass Handling Operations Scheduling. Computers and Electronics in Agriculture, 91, 49-56. http://dx.doi.org/10.1016/j.compag.2012.11.015

[3] Darby-Dowman, K., Barker, S., Audsley, E. and Parsons, D. (2000) A Two-Stage Stochastic Programming with Recourse Model for Determining Robust Planting Plans in Horticulture. Journal of the Operational Research Society, 51, 83-89. http://dx.doi.org/10.1057/palgrave.jors.2600858

[4] Guan, S., Nakamura, M., Shikanai, T. and Okazaki, T. (2008) Hybrid Petri Nets Modeling for Farm Work Flow. Computers and Electronics in Agriculture, 62, 149-158. http://dx.doi.org/10.1016/j.compag.2007.12.006

[5] Guan, S., Nakamura, M., Shikanai, T. and Okazaki, T. (2009) Resource Assignment and Scheduling Based on a TwoPhase Metaheuristic for Cropping System. Computers and Electronics in Agriculture, 66, 181-190. http://dx.doi.org/10.1016/j.compag.2009.01.011

[6] Orfanou, A., Busato, P., Bochtis, D.D., Edwards, G., Pavlou, D., Sørensen, C.G. and Berruto, R. (2013) Scheduling for Machinery Fleets in Biomass Multiple-Field Operations. Computers and Electronics in Agriculture, 94, 12-19. http://dx.doi.org/10.1016/j.compag.2013.03.002

[7] Srensen, C.G. and Bochtis, D.D. (2010) Conceptual Model of Fleet Management in Agriculture. Biosystems Engineering, 105, 41-50. http://dx.doi.org/10.1016/j.biosystemseng.2009.09.009

[8] Li, H., Yao, G. and Chen, L. (2008) Farm Machinery Monitoring and Scheduling System Based on GPS, GPRS and GIS. Transactions of the CSAE, 24, 119-122.

[9] Li, C.T., Han, X.W. and Sun, Y.Z. (2014) Design of Dynamic Vehicle Navigation Terminal Based on GPS/GPRS. ICMSE, Sanya, 237-241. http://dx.doi.org/10.4028/www.scientific.net/amm.472.237

[10] Xiao, Y. (2014) Design of Multifunction GPS/GPRS Vehicle Terminal. International Conference on Manufacturing, Singapore, 210-215. http://dx.doi.org/10.4028/www.scientific.net/amr.909.210

[11] Limited, T.N. (2015) DCM-300 Modem. http://www.trimble.com/Agriculture/dcm-300.aspx

[12] Fountas, S., Sorensen, C.G., Tsiropoulos, Z., Cavalaris, C., Liakos, V. and Gemtos, T. (2015) Farm Machinery Management Information System. Computers and Electronics in Agriculture, 110, 131-138. http://dx.doi.org/10.1016/j.compag.2014.11.011

[13] Rovira-Más, F., Chatterjee, I. and Sáiz-Rubio, V. (2015) The Role of GNSS in the Navigation Strategies of CostEffective Agricultural Robots. Computers and Electronics in Agriculture, 112, 172-183. http://dx.doi.org/10.1016/j.compag.2014.12.017

[14] Zhou, K., Leck Jensen, A., Sorensen, C.G., Busato, P. and Bothtis, D.D. (2014) Agricultural Operations Planning in Fields with Multiple Obstacle Areas. Computers and Electronics in Agriculture, 109, 12-22. http://dx.doi.org/10.1016/j.compag.2014.08.013

[15] Carballido, J., Perez-Ruiz, M., Emmi, L. and Aguera, J. (2014) Comparison of Positional Accuracy between RTK and RTX GNSS Based on the Autonomous Agricultural Vehicles under Field Conditions. Applied Engineering in Agriculture, 30, 361-366.

[16] Wattonville, J.D. (2008) 7760 Cotton Picker. ASABE, Providence, 4926-4942.

[17] Thomson, S.J. and Huang, Y. (2014) Portable Device to Assess Dynamic Accuracy of Global Positioning System (GPS) Receivers Used in Agricultural Aircraft. International Journal of Agricultural and Biological Engineering, 7, 68-74.

[18] Rowshon, M.K. and Amin, M.S.M. (2010) GIS-Based Irrigation Water Management for Precision Farming of Rice. 
International Journal of Agricultural and Biological Engineering, 3, 27-35.

[19] Luo, M., Wu, C., Cai, Y., Su, H. and Ding, L. (2012) Mobile Monitoring and Center-Navigation Technology for Agricultural Machinery. ASABE, Dallas, 29 July-1 August 2012, 5684-5695.

[20] Wu, C., Ding, L., Cai, Y., Luo, M. and Zhao, J. (2013) Development of Portable Agricultural Machinery Monitoring and Center-Navigation System. ASABE, Kansas City, 21-24 July 2013, 2649-2654. 